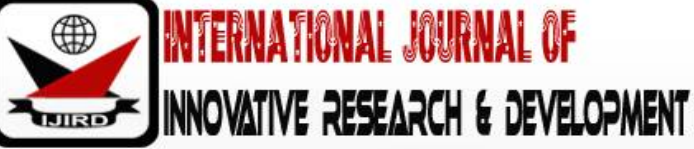

ISSN 2278 - 0211 (Online)

\section{Test Score Pollution and Performance-Based Assessment: The Thinking among Students of the University of Education, Winneba, Ghana}

\author{
Dr. Samuel Asare Amoah \\ Lecturer, Department of Psychology and Education, University of Education, Winneba, Ghana
}

\begin{abstract}
:
This study explored students' views on Test Score Pollution (TSP) and how they practised Performance-Based Assessment (PBA) and whether there was any relationship between TSP and PBA test scores. Descriptive survey design of a quantitative approach with 260 participants, selected through the multistage sampling technique was used. A questionnaire eliciting responses from participant on TSP and PBA was the data collection instrument. Descriptive statistics, mean and Spearman's Correlation were the analytical tools. The results indicate that students did not have much knowledge on TSP and that PBA scores were contaminated. There was a strong positive correlation in the views expressed by students between TSP and PBA scores. It is concluded that better understanding of TSP is good since PBA scores can be influenced by TSP. It is therefore recommended that assessment experts need to get students understand what TSP is all about.
\end{abstract}

Keywords: Test score pollution, performance based assessment, high-stakes test, true score, error score, observed score

\section{Introduction}

Misuse and overuse of test results due to high pressure on the urge to produce high test score and the equating of test scores with educational improvements have generated lots of argument in the assessment environment (Amoah, Inkoom, \& Gyamera, 2018). These can be traced back to the 1990's when Haladyna (1991) lamented that the high-stake in test scores facilitates TSP which is linked to the sources; test preparation, situational and other factors such as cultural and psychological issues. The National Council on Measurement in Education (NCME, 2014) describes a test as "a device or procedure in which a sample of an examinees' behavior in a specified domain is obtained and subsequently evaluated and scored using a standardised process" (p2). Debatable concerns on test results abound worldwide, hence, reform efforts have been made over the past two decades. Concentration on interventions that hold schools accountable for student learning through comparison of test scores (Jones, Jones, Hardin, Chapman, Yarbrough, \& Davies, 1999) performancebased assessment (PBA) was recommended.

Some of these interventions (Alternative Review Group, 2002; Black \& William, 1998; Office for standards in Education, 2003, United States of America (USA); Bol, Nunnery, Stephenson \& Mogge, 2000) have led to the use of PBA which is seen to be bringing quality in teacher assessed scores that is based on goals or objectives of the curriculum that a student is mastering. In PBA, value judgments are made on constructs. However, the decisions made are observed to be unavoidably incomplete and somewhat error prone. Contributing to this debate, Anane (2008) posits that the validity and value of test scores are compromised and not safe to be used for decision making, especially in PBA and TSP which is supporting the increasing debate recently by the public about test results.

Numerous studies have expanded the scope of research on TSP and PBA separately, for example, a number of factors affect test scoring in PBA. Agbenyo (2017) laments that teacher's claim that students, when given assignments rely mostly on using previous assignment solution in solving current ones. Again, it is recorded that teachers prepare students seriously on assignment and homework given them (Agbenyo, 2017). Further, Thomas, Hertzig, Dryman, and Fernandez (2001) believe that cultural dimensions play important roles in the success of the leaners and their test scores. In addition, researches conducted on TSP and PBA across the world indicate how teachers use variety of assessment strategies, when indeed teachers are limited in ensuring effective skills in terms of PBA hence, score pollution is evident (Alkharusi, Kazem, \& Al-Musawai (2011). Bekiroglu (2009), surveying 38 English teachers, discovered that PBA is accepted depending on the grading or the scoring issues which most of the time are contaminated. These studies tend to point to the fact that test scores are crucial in decision making; however, as pointed out by Azizeh and Mansoor (2010), TSP seriously affects the truthfulness of test score interpretation and brings into doubt the reasonableness of many of the uses of test score. While these studies concerned with teachers' TSP and PBA their results may not offer information needed to fully link TSP and PBA in the context where high-stake tests are used to make decision in UEW. 


\subsection{Rationale of TSP and PBA}

When a score does not represent what has been achieved under PBA, then it undermines the validity of any inference drawn from that test and any decision based on these inferences. Therefore, if under PBA learners are made to learn to test, the influence may be subtle, but as it grows it can lead to harmful effect. Subject areas and intellectual activities that the assessment does not measure may receive less attention hence, learners may resort to using unorthodox way to get good scores. In effect, minimizing TSP and its effect on PBA include (Haladyna, 2002-test security; Nitko, 2004preparing students for testing; Sundeme, 2019-uniformity and security of test administration; Tavakoli, 2007-use of different assessment procedures.

Using the measurement theory, (Spearman, 1904) where true score exists for the concept to be measured. The true score theory is related like;

$\mathrm{X}($ Observed Score $)=\mathrm{T}($ True Score $)+\mathrm{E}($ Error score $)$

This theory maintains that every measurement comprises the true score and error components. This suggests that whatever score that is identified may not be accurate reflection of reality. This means the error components either inflate or deflate test scores, hence, in PBA, where scores determination is dependent on the assessor, whose actions may be influenced by TSP, results from PBA may not offer credible information needed to justify and fully explain the real performance of individuals on the assessment. Whatever is observed may be coming from either an inflated score or deflated score due to the error components as explained by the true score theory. The use of high stakes testing is pervasive and results have become a standard point of reference for authorities to make decisions in life-changing situations (Hartono, 2019). Hence, it is suggestive that when PBA scores are polluted, they will not provide right scores of the individual. It is therefore necessary to ensure that issues that can influence the performance of testees need to be given much attention, because there exists positive relationship between test-anxiety and test-taker performance as posited by Hartono (2019).

\subsection{The Problem}

In measuring constructs like, anxiety, writing good report, making presentations, scoring high marks on demonstration, essay writing, portfolio scoring which are all PBA-based as used in this study, each of these components has some relationship in TSP (Haladyna, 2002; Sundeme, 2019, Agbenyo, 2017). In most countries including Ghana, little or no attention has been given to what pertains in the universities, especially University of Education, Winneba (UEW). Thus, the impact of TSP on the True score (TS) of individual learners becomes too glaring to be overlooked in our modern educational dispensation. In Ghana, for example, and most nations, there seem to have been some researches on knowledge level as well as sources of TSP and PBA practices and their impact on students' academic performances (Asare, 2015; Agenyo, 2017; Sundeme, 2019; Anane, 2008). No particular study has been done to explore the views of students on the issues relating to TSP and PBA and their relationships to students' academic performances in general, or UEW students in particular. In view of this this study seek to explore on students view on TSP and PBA scores and how they are related.

UEW students lament on test results they obtain either from their mid-semester quizzes scores or end of term examinations scores. Assessor factors, environmental factors, test administration factors as well as scoring factors have dominated the students' complaints. However, no empirical study has been undertaken to ascertain the knowledge level in TSP and scores from PBA practices of UEW students. This therefore urged the researcher to embark on an empirical study to assess the knowledge level of students on how test scores they obtained were contaminated, because it had been identified that TSP influence teaching and learning (Agbenyo, 2017). Again, it has been argued that there is the difficulty in developing effective assessment plan to ensure there is no test pollution (Sundeme, 2019; Amedahe, 1989; Etsey, 2003) especially among Ghanaian teachers who lack the requisite skills (which can pollute test scores), in constructing, administering and evaluating test and test scores as posited by Amedahe (1989) and Etsey (2003).

Further, in view of the fact that several studies (Abgenyo, 2017; Sundeme, 2019) have come out to look at TSP and PBA practices, and since no empirical study has been done in UEW, this study sought to explore students' views on how the scores they obtain in any assessment process were contaminated. It becomes evident that the problem under study has indeed implications for both students and assessors as well as policy formulation.

\subsection{Purpose}

The purpose was to explore students' view on TSP, PBA and how TSP and PBA are related.

\subsection{Objective}

- Establish students' understanding of test score pollution

- Explore concerns on PBA scores by students

- Establish the relationship between TSP and PBA

\subsection{Lens of Analysis}

- What are university students' perception of test score pollution?

- What are university students' concerns on PBA scores?

- To what extent does TSP correlate with PBA performance in the university?

\section{Methodology}

Descriptive survey design using the quantitative approach, was employed for this study. Description emerges following creative exploration, and serves to organize the findings in order to fit them with explanations, and then test or 
validate those explanations (Krathwohl, 1993). Further, survey research involves collecting data to answer questions concerning the phenomenon under study, and is used to describe the nature of existing conditions, identify standards against which existing conditions can be compared, and/ or investigates the relationships that may exist between events (Amoah, 2011).

\subsection{Profile of Department and Participants selected for the study.}

The Psychology and Education Department is one of the departments of the University of Education, Winneba. The department supports other departments of the university to prepare professional teachers to teach in the Ghanaian education service. The department has professional and assessment expert lecturers. One of the courses that is being run in the department is Measurement, Evaluation and Statistics. This course acquaints students with educational assessment principles, methods and practices necessary for school teachers. The course is designed to equip students with various ways of effectively and efficiently assessing and interpreting learning outcomes of students. Not only will the teacher use the results for further teaching, but will also be equipped to use the results to support the guidance and counselling programme in the schools.

The participants were student-teachers who were already teaching but were not professional teachers. They enrolled as Post Graduate Diploma in Education (PGDE) students in the Department of Psychology and Education, to become professional teachers. Whilst teaching they had been assessing their students, and since they enrolled, they had been given tuition on better assessment techniques. They were thus, selected to be used because of their unique characteristics and were believed to be able to give better responses based on their experiences.

\subsection{Participants and Procedure}

Purposive, stratification and simple random sampling techniques were employed to select the participants for the study. A total of 260 students on the PGDE programme were randomly selected through the lottery method. Also, the PGDE programme (students) were selected because they were nonprofessionals whose training would require them to be able to give true assessment of their students in the context of the knowledge in TSP and PBA.

\begin{tabular}{|c|c|c|c|}
\hline $\begin{array}{c}\text { Psychology and Education } \\
\text { Department (PGDE Students) }\end{array}$ & Population & $\begin{array}{c}\text { Number of Students } \\
\text { Selected (Sample) }\end{array}$ & $\begin{array}{c}\text { Percentages } \\
\text { (\%) }\end{array}$ \\
\hline Year 1 & 480 & 120 & 46.0 \\
\hline Year 2 & 560 & 140 & 54.0 \\
\hline Totals & 1040 & 260 & 100.0 \\
\hline \multicolumn{3}{|c|}{ Table 1: Distribution of Selected Students } \\
Source: Fieldwork Data (2019)
\end{tabular}

\subsubsection{Instrumentation}

The data collection instrument was researcher constructed questionnaire. The questionnaire (27 items) was in three sections A, B, and C. Section A (3 items) sought information on the demographic characteristics of the respondents. Section B (16 items) focused on students' perception on test score pollution and section C ( 8 items) was on students' views on where assessors could influence PBA scores they obtained. In sections B and C, the response mode was in a 4-point Likert-type scale ranging from Strongly Agree (4), Agree (3), Disagree (2), and to Strongly Disagree (1) on issues raised under TSP and PBA practices. A critical value for the determination of means was calculated to be $2.5[(1+2+3+4) / 4=2.5]$. The internal consistency of the instrument yielded Cronbach Alpha of .87. for TSP and 0.88 for the PBA sections respectively.

\subsubsection{Analysis}

Arithmetic mean and standard deviation were used to analyse research questions 1 and 2, whilst Spearman correlation statistic was used to analyse research question 3.

\section{Results}

\subsection{Research Question 1}

\subsubsection{What Are University Students' Perception of Test Score Pollution?}

Table 2 presents the analysis for research question 1 


\begin{tabular}{|c|c|c|c|}
\hline Students' Views TSP & \multicolumn{2}{|c|}{ Cvalue=2.5 } & Remarks \\
\cline { 2 - 3 } & Mean & Std. Dev & \\
\hline $\begin{array}{c}\text { When students are taken through test taking skills it influences their } \\
\text { performance to obtain good score }\end{array}$ & 2.809 & .7946 & High Knowledge \\
\hline Look at previously marked item before marking a new question & & & \\
\hline Marking students work under chaotic environment & 2.665 & 1.015 & High Knowledge \\
\hline Ambiguous instructions prevent students to put up best performance & 2.163 & .4952 & High Knowledge \\
\hline I always use marking scheme when marking & 2.085 & 1.549 & Low knowledge \\
\hline I mark questions item by item and not script by script & 2.020 & .5920 & Low knowledge \\
\hline Experiencing anxiety in test taking contributes to my performance score & 2.942 & .6526 & High knowledge \\
\hline Fatigue during test taking makes student not performing well & 2.925 & .6377 & High knowledge \\
\hline $\begin{array}{c}\text { Students have problems of organizing their thoughts in holistic and } \\
\text { coherent manner }\end{array}$ & 1.835 & .3714 & Low knowledge \\
\hline Test taking Environment ideal & 1.756 & .4293 & Low knowledge \\
\hline I continue marking when I am tired & 1.596 & .4909 & Low knowledge \\
\hline Test administration well done & 2.691 & .4339 & High knowledge \\
\hline My name is always written on assignment sheets & 1.406 & .4915 & Low knowledge \\
\hline Students develop self-assessment model & 1.925 & .6377 & Low knowledge \\
\hline $\begin{array}{c}\text { The cooperation I have with other students while preparing } \\
\text { assignments influences my performance score }\end{array}$ & 1.835 & .3714 & Low knowledge \\
\hline Students depend on my marking decision & & & \\
\hline Means of means & 2.186 & .4293 & Low knowledge \\
\hline Table & 0.6362 & \\
\hline
\end{tabular}

Table 2: Arithmetic Mean Analysis on Students' Perception of Test Score Pollution Source: Fieldwork Data (2019)

From the results in Table 2, the mean of mean score of 2.186 as compared to the critical mean score of 2.5 shows that on the whole students do not know that their perception on some of the activities involved in assessment is what TSP is about. This is evident from the mean of means value ( $\mathrm{M}=2.186, \mathrm{SD}=.6362)$ which is less than the cutoff point of 2.5. However, few issues from the results give credence to the fact that those activities related to TSP. Students taken through test taking skills to support them obtain good score ( $\mathrm{M}=2.809, \mathrm{SD}=7946)$, Look at previously marked item before marking a new one question ( $M=2.665, S D=1.015)$, Marking students work under chaotic environment $(M=2.571, S D=4952)$, Ambiguous instructions prevent students to put up best performance ( $\mathrm{M}=2.163, \mathrm{SD}=7899)$ I always experience anxiety in test taking ( $M=2.942, S D=6526)$, Fatigue during test taking make student not performing well $(\mathrm{M}=2.925, \mathrm{SD}=6377)$. Further, I always use marking scheme when marking $(\mathrm{M}=2.085, \mathrm{SD}=1.546)$, I mark questions item by item and not script by script ( $\mathrm{M}=2.020, \mathrm{SD}=.5920)$ are the indicators from the view point of the students that do not contribute to TSP. These findings support the views expressed by Abgenyo (2017), Anane (2008), and Haladyna (1992) who indicated that there are some activities that provide basis for TSP especially in high stake achievement test.

\subsection{Research Question 2}

\subsubsection{Where Are University Students' concerns on PBA scores?}

Table 3 presents the analysis for research question 2 . This result is about where the students feel assessors' behaviours can influence scores obtained by students.

\begin{tabular}{|c|c|c|c|}
\hline \multirow[t]{2}{*}{ Students' Concerns } & \multicolumn{2}{|c|}{ Cut off point=2.50 } & \multirow[t]{2}{*}{ Remarks } \\
\hline & Mean & Std dev & \\
\hline I always have problems with the marks I obtain from given Group work & 3.72 & .878 & Practice \\
\hline I always think I score high marks during demonstration activities & 3.64 & .970 & Practice \\
\hline $\begin{array}{l}\text { My assessment score from presentations on practicum exercises is always } \\
\text { debatable }\end{array}$ & 3.49 & .880 & Practice \\
\hline $\begin{array}{c}\text { The teacher established format of assessment affect my thinking in Essay } \\
\text { writing }\end{array}$ & 3.76 & .810 & Practice \\
\hline The criteria used to score my work does not relate to my performance & 3.38 & .963 & Practice \\
\hline $\begin{array}{l}\text { The way that I am assessed make me do surface learning during individual } \\
\text { projects }\end{array}$ & 3.46 & 1.56 & Practice \\
\hline Made to write reports on practicum & 3.95 & .456 & Practice \\
\hline $\begin{array}{l}\text { Specific judgment with justification is involved when I am assessed on a } \\
\text { given homework }\end{array}$ & 2.99 & .954 & Practice \\
\hline Mean of Means & 3.31 & 0.934 & \\
\hline
\end{tabular}

Table 3: Mean Analysis Results on Students' Concerns on PBA Scores

Source: Fieldwork Data (2019) 
From Table 3, it could be deduced that generally the students show concerns on how assessors influence the scores they obtain in the practice of PBA. In the areas of writing of essay $(\mathrm{M}=3.67, \mathrm{SD}=.935)$, doing demonstrations $(\mathrm{M}=3.64, \mathrm{SD}=970)$, Make presentations on practicum exercises $(\mathrm{M}=3.49, \mathrm{SD}=.880)$ were what the student show much concern on how assessors influence scores they obtain in PBA with writing of reports on practicum $(\mathrm{M}=3.95, \mathrm{SD}=456)$ being the one that students came out to say scores obtained are manipulated by assessors. However, one area that much concern was raised was on given homework ( $\mathrm{M}=2.99, \mathrm{SD}=.954)$. These findings do not support Zhang and Burry-Stock in Sundeme (2019) that there are contradictions in the way PBA scores are awarded and how it is practiced in the USA, but with the study findings the students thought they did practised PBA which was in line to what Alkharusi, Kazem, \& AlMusawai (2011) talked about.

\subsection{Research Question 3}

To what extent does TSP correlate with PBA scores in the university?

Table 4 presents the analysis for research question 3

\begin{tabular}{|c|c|c|c|}
\hline & & TSP & PBA \\
\hline TSP & Correlation & 1.000 & .849 \\
\hline & Sig (2-tailed) & .000 & \\
\hline & $\mathrm{N}$ & 260 & \\
\hline PBA & Correlation & .849 & 1.000 \\
\hline & Sig (2-tailed) & .000 & \\
\hline & $\mathrm{N}$ & 260 & \\
\hline
\end{tabular}

Table 4: Correlation Results on TSP and PBA Scores

Source: Fieldwork Data (2019)

From Table 4, it is suggested that TSP has a significant relationship with the PBA scores. However, there is significantly strong relationship (.849) between the responses of the respondents that said TSP has significant relationship with the PBA scores. With a positive correlation of 0.849 , it shows a very strong relationship. This is indicative that TSP has a relationship with the PBA scores hence, the need for special attention.

\section{Discussions}

The study revealed that the students, even though show less knowledge in TSP, felt there were issues that contribute to TSP. Taking students/ learners through test-taking skills, from the study, contributes to TSP. this supports Boud and Holmes (2003) argument and tends to support a similar research reported by Nolen, Haladyna and Haas (2000) which was of the fact that $60 \%$ of teachers they surveyed taught that this indicator support students to perform well. Further, teachers' marking skills and ambiguous instructions contribute to TSP from the results. This supports Boud (2003) idea that students can perform well in any test if clear and the teachers' marking skills are up to date. On the issue of experiencing test anxiety, it has influence on test scores because, Gardner and Moorcroft (2005), Dornyei and Schmidt (2001) and Cushing and Purpora in Sundeme (2019) all argued that it has an influence on scores that students obtain. This then supports the outcome of the study where test anxiety influences TSP. These discussions indicate that if unethical practice inflates test scores, one can no longer infer that a good score indicates mastery of the larger content domain being sampled by test. TSP then is seen to be highly multifaceted phenomenon which provides an excellent example of how students view PBA scores.

Relying on the study of TSP and PBA, nine prototype of actions which could be expressed in TSP are; When students are taken through test-taking skills it influences their performance to obtain good score; Looking at previously marked item before marking a new one question, Marking students work under chaotic environment, Ambiguous instructions prevent students to put up best performance, use marking scheme when marking; mark questions item by item and not script by scrip; experiencing anxiety in test taking contribute to performance score; Fatigue during test taking makes student not to perform well.

It came out from the study that self-assessment scores, criteria used to score portfolio and the teachers' established assessment format which affect the thinking of students in essay writing in PBA and issues where scores are contaminated are in line to what Boud (2003) proposed. However, the findings become interesting when compared with what Sundeme (2019) came out with, which relies on average on teachers' view.

Finally, it was also found that there was a moderate, positive correlation between the TSP and PBA scores. This result is in line with Yayra (2018) and Agbenyo (2017) on the relationship between test anxiety and test takers performances, even though anxiety was one of the multifaceted variables in TSP. Further the study findings affirm Alkharusi, Kazem, \& Al-Musawai (2011) study results in Oman among 233 in-service teachers since teachers use variety of assessments in the classroom to assess their students.

\section{Conclusions}

The current study revealed that generally, the university students did not have better understanding of TSP but were aware that decisions were made on test scores hence the true performance of students became a mirage since what they observed as their performance was not wholly true. Further, the study revealed that the students practised PBA and were scored based on what they produced as buttressed by the findings that suggest that there is a positive relationship between TSP and PBA scores. 
In the present discussion, the teacher-students exhibited behaviors in TSP issues are instructive examples of what Spearman (1904) argues on assessment actively exhibited behaviors pointing to TSP. The result underscore Spermans (1904) argument that X(Observed Score $)=\mathrm{T}($ True Score $)+\mathrm{E}($ Error score $)$

context do exert influence on teacher's behavior in PBA. Although TSP and PBA relate to each other, the two issues typically have not been linked together thematically in the past. It is therefore concluded that PBA scores have some association with TSP.

\section{Recommendations}

It is recommended that students are made aware by teacher educators, assessors and lecturers in the context of the study that some factors contribute to the score they obtain in assessment. Hence test scores cannot be wholly be an indicator of performance of learners on a test. This should be highlighted deeply when giving feedback to students on PBA scores.

Again, there is the need for collaboration (Self-, peer assessment), between assessors, students, stakeholders who use assessment results for decision making, and policy implementers to avoid some negative effects of unilateral assessment. This is because assessment messages are coded, not easily understood and are often read differently and with different emphasis. Further good assessment is not just a matter of the findings but using the results sensibly in conjunction with given subject matter.

Assessment procedure of high consequential validity need to be developed, by institutions in consultation with assessment experts, students and assessors in universities, since TSP's influence on PBA scores is a challenge. This is because decision making should support students to learn and relate what is learnt in order for the one to be functional within the context the individual finds him/ herself.

\section{Limitation}

One obvious limitation from this study was the use of one department even though all departments in the university take a general course called measurement, evaluation and statistics, hence generalization is problematic. Another important point to note is that correlation is not causation and must never be considered as one, since the study context and analysis was done only to establish relationship.

\section{References}

i. Agbenyo, S. (2017). Determinants of test score pollution in junior high schools in three selected Districts in the Volta region, Ghana. Unpublished Master of Philosophy in Measurement and Evaluation. Cape Coast. University of Cape Coast.

ii. Alkharusi, H., Kazem, A., M. \& Al-Musawai, A. (2011) Knowledge, skills, and attitudes of preservice and in-service teachers in educational measurement Asia-Pacific Journal of Teacher Education, 39(2) 113-123

iii. Amedahe, F. K. (2004) Notes on educational research. Unpublished document. University of Cape Coast.

iv. Amoah, S. A. (2011). The Reflective and Collaborative Practices of Teachers in Ghanaian Basic Schools: A Case Study. Unpublished PhD Thesis. Nottingham. University of Nottingham, UK.

v. Amoah, S. A. Inkoom, D \& Gyamera, A. (2018) Relationship between perceived parenting styles and self-esteem of senior high school students in Ghana. International journal of basic education research and policy (IIJOBERP), vol $1,2, \mathrm{pp} 103-125$

vi. Anane, E. (2008). High stakes testing, curriculum implementation and interaction. Cape Coast. University of Cape Coast Press.

vii. Azizeh, C., \& Mansoor, T. (2010). Sources of test score pollution: State of the art Unpublished Master's Thesis. Islamic Azad University, Khorasgan Branch Isfahan.

viii. Boud, D. (2003). Enhancing learning through Self-assessment. London: Routledge Falmer

ix. Boud, D., \& Holmes, H. (2003). Enhancing learning through Self-assessment. London: Routledge Falmer-Taylor and Francis Group. In David Boud (2003)

x. Dornyei, Z. \& Schmidt, R. (Eds) (2001). Motivation and second language acquisition. Honolulu, HI: University of Hawaii Press.

xi. Etsey, Y., K (2005) Assessing performance in schools: Issues and practice. Ife Psychologia 13(1): 123-135.

xii. Gardner, R., \& Moorcroft, R. (2005). The role of attitudes and motivation in second language learning: Correlation and experimental considerations. Language Learning, 35, 207-227

xiii. Haas, N. S., Haladyna, T. M., \& Nolen, S. B. (1990). Standardised testing in Arizona: interviews and written comments from teachers and administrators. (Technical report 89-3). Phoenix, AZ: Arizona State University West.

xiv. Haladyna, T. (1991). Test score pollution: implication for limited English proficient student. In proceedings of the $2^{\text {nd }}$ national research symposium on limited English proficient issues. Focus on evaluation and measurement. (vol. 2, pp135-163) Washington DC. US department of Evaluation office of bilingual education and language affairs.

xv. Haladyna, T., Nolen, S., B., \& Haas, N. (2000). Raising standardized achievement test scores and the origins of test score pollution. Educational Researcher, 20 (5), 2-7.

xvi. Hartono, D. A. (2019). Investigating the relationship between test-taking anxiety and test-takers performance on the IELTS test. Script journal: Journal of linguistic and English teaching. 4(1), 1-11

xvii. Jones, M. G., Jones, B. D., Hardfin, B., Chapman, L., Yarbrough, T., \& Davis, M. (1999). The impact of high-stakes testing on teachers and students in North Carolina. Phi Delta Kappan, 81 (3), 199-203.

xviii. Krathwohl, D. R. (1993). Methods of educational \& social science research: An integrated approach. White Plains, 
New York: Longman.

xix. National Council on Measurement in Education (NCME) (2014). Standards for educational and psychological testing. Washington, DC.

xx. Neil, M. (2010). Reduce standardized testing to improve accountability, school quality. Retrieved on 10 May 2019 from http/ / idea.gsei.ucla.edu/ newsroom/ education news roundup.

xxi. Nitko, A. J. (1996). Designing tests that are integrated with instruction. In R. L. Linn(Ed), Educational Measurement (3rd), (pp447-471). New York: American Council on Education.

xxii. Nolen, S. B., Haladyna, T. M., \& Haas, N. S (1992). A survey of actual and perceived uses, test preparation activities, and effects of standardized achievement test. Educational Measurement Issues and Practices.

xxiii. Sundeme, B. (2019). Teachers' Knowledge and Practice of Performance-Based Assessment in the Junior High Schools in the Berekum Municipality, Ghana. Unpublished Master of Philosophy thesis. Cape Coast. University of Cape Coast.

xxiv. Thomas, A., Hertzig, M., Dryman, I., Fernandez, P. (2001). Examiner effect in IQ testing of Puerto Rican workingclass children. American Journal of Orthopsychait, 41(5), 809-821.

xxv. Yayra, D. (2019). The Influence of Demographic Variables on Test Anxiety of Undergraduate Students. The international journal of innovative research and development, 8(2), 11-26 DOI:

10.24940/ ijird/ 2019/v8/i2/ FEB19013 